\title{
The prevalence of Cyberloafing among pupils belonging to the digital native's generation
}

\author{
Nadezhda Sivrikova ${ }^{1, *}$, Tatyana Ptashko ${ }^{1}$, Svetlana Roslyakova ${ }^{1}$, Nadezhda Sokolova $^{1}$, and Rifkat Dimuhametov ${ }^{1}$ \\ ${ }^{1}$ Department of Social Work, Pedagogy and Psychology, South Ural State Humanitarian Pedagogical University, 69 Lenin Ave., \\ Chelyabinsk, 454080, Russia
}

\begin{abstract}
The purpose of this research was to study the prevalence of cyberloafing among students in the classroom. 150 (66 are boys and 84 are girls) schoolchildren living in the Ural region of the Russian Federation between the ages of 13 and 15 took part in the study. The scale of cyberloafing by Y. Akbulut et al., translated into Russian used for the collection of empirical data. Student's T-criterion was used to analyze differences in cyberloafing levels in children of different sexes. The results of the research showed that during lessons they are most often interested in content and communicate with friends. The girls are more prone to cyberloafing than the boys. Girls are more likely to go to social media lessons and communicate online. Boys are more likely to play on the lessons in games on their mobile gadgets.
\end{abstract}

\section{Introduction}

The generation of modern schoolchildren is growing into the environment of information technologies. As a result, these children differ greatly from their parents and teachers in childhood in communicative skills, type of thinking, speed of information processing, etc. They are used by information technology everywhere, including in the classroom. A new term appears to refer to them, "digital natives". Differences in the social situation of development create conditions for intergenerational gaps and create new risks in the education system, which are insufficiently studied. Such risks include the use of information and communication technologies in classes for nonlearning tasks - cyberloafing.

Researchers found that the use of digital technologies in the classroom leads to increased motivation of students $[1,2]$, learning reading and language skills [3]. However, there are also negative consequences of using digital devices (tablets, smartphones, laptops, etc.) in the classroom during the lesson. This activity poses a serious threat to the student's understanding of educational material [4], degrades the storage and reproduction of educational material [3], negatively related to academic performance [5]. Researchers point out that dominance in the entertainment content network distracts of schoolchildren from solving educational problems [6].

Thus, if students have access to digital technologies during the lesson, they can use Internet technologies to solve educational and personal problems. These tasks can compete among themselves. Researchers acknowledge that using the internet during a lesson to achieve personal (non-learning) goals - Cyberloafing is a problem that has

*e-mail: bobronv@cspu.ru only been increasing recently [7]. A review of literature on this topic showed that: 1) much attention is paid to cyberloafing in the business sphere, but not in the education system; 2) foreign research on cyberloafing in the educational environment is mainly piloting. There is no such research in Russia. This can be explained by various reasons. First, there are no methods of measuring cyberloafing in Russian. Second, there is a low level of awareness of the scale of cyberloafing in modern schools. Therefore, the purpose of this research was to study the prevalence of cyberloafing behavior among school students.

\section{Theoretical background}

\subsection{Cyberloafing}

The concept of cyberloafing appeared in the scientific literature in the west in the early 2000s. V.K.G. Lim [7] proposed using it to designate the voluntary use by employees of Internet access in the workplace to solve nonwork-related tasks during working hours. The meaning of the term has been refined and expanded over time.

The use of any digital technology and mobile devices for personal purposes in the workplace has been added to the content of cyberloafing $[8,9]$. Besides cyberloafing there are many terms explaining the same or similar behavior like non-work related computing, cyberslacking, cyberbludging, on-line loafing, internet deviance, problematic internet use, personal web usage at work, internet dependency, internet abuse, internet addiction, and internet addiction disorder [10]. They all focus on employees using technology devices to pursue personal goals instead of working tasks.

Cyberloafing is seen as a special form of psychological protection (care) through the use of information technolo- 
gies [9]. It raises serious concerns among the heads of organizations, as it causes numerous problems [11]. This can be manifested in the tendency of employers to hire older people at equal levels of experience. Managers' tendency towards older people is mainly due to their higher level of reliability and professionalism compared to younger workers. Given that digital natives represent the workforce of the future, their perceived lack of diligence poses a growing challenge to organizations [12]. This problem becomes new in light of the study of the phenomenon of cyberloafing, which is also associated with the age of workers.

Researchers view cyberloafing as a type of counterproductive deviant behavior in the workplace [13-15]. But cyberloafing is different from classic versions of counterproductive behavior, such as theft at work, sexual harassment, deliberate delay, etc. It's linked to boredom in the workplace [16] and has positive effects such as minimizing stress, improving mood [17] and self-education [18].

Researchers are engaged in discussions about the structure of cyberloafing. V.K.G. Lim proposed a twofactor cyberloafing model. The author believed that cyberloafing consists of 2 types of activity: hanging on the Internet and using e-mail (a browsing or e-mailing activity) [15].

According to this concept, M. Anandarajan, P. Devine, and C. A. Simmers [19] cyberloafing include destructive behavior, the desire to entertain oneself, self-education, and ambiguous use of the Internet. The merit of this approach is to take into account the goals of cyberloafing. However, it is based on a person's subjective perception of the utility and appropriateness of a certain behavior, and not the behavior itself.

A. L. Blanchard and C. A. Henle suggested that cyberloafing can take two forms: minor cyberloafing (for example, sending and receiving personal email at work) and serious cyberloafing (for example, online gambling, viewing pornography, participating in chats, and viewing blogs). This model is useful in studying the consequences of cyberloafing [20].

S. Yasar distinguished four forms of cyberloafing: individual (shopping, travel, job search, carrier, and online banking), social (personal or group chat, social networking sites, discussion boards, instant messaging, and e-mail), search (searching, pictures, video on search engines, etc.), and news (news, sport, weather sites, and bulletin boards etc.)[21].

Thus, it can be concluded that there are different forms of cyberloafing behavior that can be isolated from different bases. In addition, the emergence of new technologies leads to the emergence of new forms of cyberloafing.

\subsection{Cyberloafing in the academic sphere}

A review of research on cyberloafing shows that this phenomenon is actively studied in the business environment [7, 11, 17]. But, this phenomenon is present in other spheres, for example in the academic environment $[3,5,17,22]$. Researchers note that the sphere of education belongs to one of those areas where the Internet is used most intensively [23]. The proliferation of mobile technologies and wireless networks brought not only new opportunities but risks to education too. Use of information and communication technologies in non-learning classes - cyberloafing can be attributed to risks [24].

Cyberloafing is seen as a barrier to the successful integration of information and communication technologies into the educational environment [25]. In the field of education, the subjects of cyberloafing can be 2 parties: teachers and students. At the same time, empirical evidence suggests that students are more susceptible to cyberloafing than teachers [26].

Researchers view cyberloafing behavior among teachers as an obstacle to professional duties that refers to the side effects of using devices with internet access. They suggest that cyberloafing may be one of the symptoms of professional burnout of an Internet teacher [17]. In general, this phenomenon has not been sufficiently studied to date.

The attention of researchers is drawn by studying the level of cyberloafing among studying (school and university students). First of all, the reasons for using Internet technologies in the lesson to solve non-educational problems are analyzed. E. Ergun and A. Altun highlight the following causes of cyberloafing: motivation, goals, teacher, environment and time [27]. Other authors add the following items to this list: course content, student identity and level of information technology ownership [17, 22]. The results of studies of personal predictors of cyberloafing of students revealed that this type of behavior in the lesson is influenced by psychosocial perceptions, attitudes, and strategies of training, but not educational motivation [5]. Researchers refer to environmental factors associated with students cyberloafing behavior. They are class level, family income, and place of residence [28].

Research has shown that cyberloafing behavior exists in a modern school. However, its distribution depends on the quality of Internet technologies in the country and on their use in school [13, 23, 29]. Researchers point out that in schools, different types of cyberloafing behavior can be observed in school students sometimes or rarely.

Thus, researchers view cyberloafing as a harmful distraction in the classroom that can have a positive effect under certain conditions. In particular, researchers recognize the potential of cyberloafing as a means of recovery [5].

\section{Method}

150 schoolchildren living in the Ural region of the Russian Federation between the ages of 13 and 15 took part in the study. Of these, 66 are boys and 84 are girls. The study was conducted during the summer holidays to reduce the impact of fear of punishment.

The scale of cyberloafing Y. Akbulut et al., translated into Russian it was applied for the collection of empirical data. A personal information form to address the background variables of the study was followed by the scale. 
The cyberloafing scale addressed the frequency of 27 cyberloafing behaviors which ranged from 1 (never) to 5 (a great extent).

Factors of the scale were sharing information (3 items such as posting content, chatting, leaving comments), shopping (6 items such as online shopping, auctioning, banking), activity on social networks ( 9 items such as publish posts on social networks, read posts on social networks, likes posts on social networks), accessing online content (6 items such as downloading music, videos and applications) and socialization (3 items such as updating status on social networks, mark friends in photos).

Table 1 shows the results of the reliability analysis of the measuring device used by Cronbach's alpha. Cronbach's alpha is a measure of internal consistency, that is, how closely related a set of items are as a group. It can be written as a function of the number of test items and the average inter-correlation among the items.

The original scale was developed with 150 schoolchildren [29].

The explained variance was $63.7 \%$ for the sample. Cronbach's alpha coefficients were high for the total scale (0.932) and individual factors as follows: sharing information (0.813), shopping (0.881), activity on social networks $(0.839)$, accessing online content $(0.867)$ and socialization (0.775).

Student's T-test for independent samples was used to analyze differences in cyberloafing levels in children of different genders. All analyses performed in this study were conducted using the Statistical Package for the Social Sciences (SPSS) version 23.0.

Skewness and kurtosis values were between -2 and +2 , so the normal distribution assumption was met (see table 2).

\section{Findings}

Data indicate that schoolchildren use the Internet to search for information and communicate online during lessons more often than other types of cyberloafing behavior. Schoolchildren shop and share information during lessons rarely. These characteristics are observed among both boys and girls.

Descriptive statistics along with parametric test results are summarized in table 3 .

Analysis of differences between respondents of different sexes showed that girls are more prone to cyberloafing than boys. Similar data were obtained when studying the use of smartphones by students from China [30].

Girls are more likely to go to social media lessons and communicate online (figure 1, figure 2).

\section{Discussion}

In the study presented, the level of cyberloafing in schoolchildren indicates that they use Internet access during lessons to solve non-learning problems rarely or sometimes. Similar data on the prevalence of cyberloafing were found on samples of students from Turkey [3, 31] and Turkish students of 6th-8th grade [32].

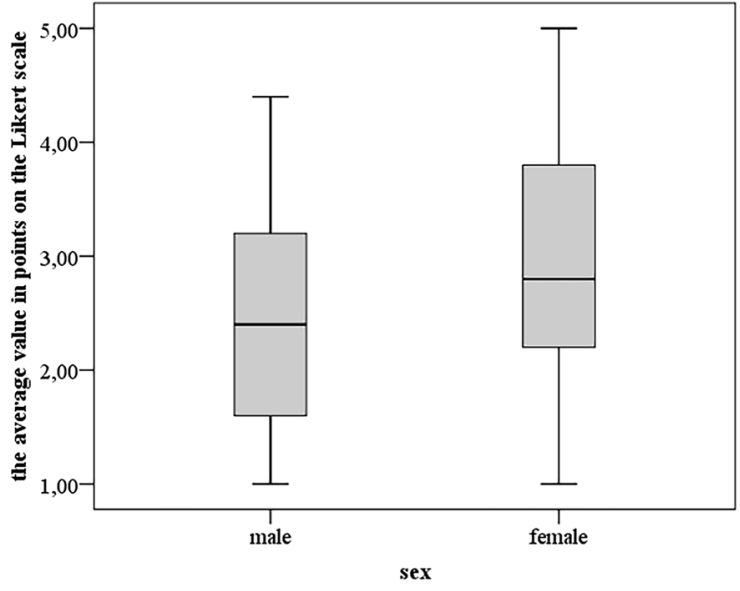

Figure 1. Social media activity during the lesson

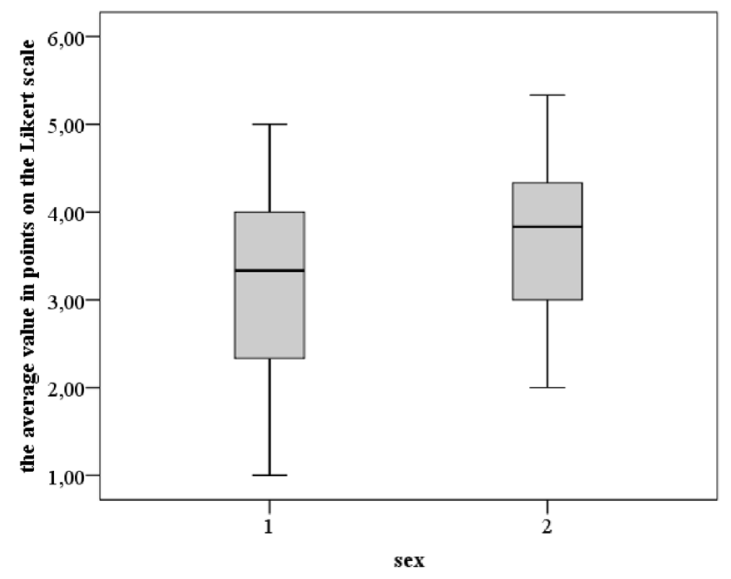

Figure 2. Communicate with friends (socialization) online during lessons

The differences concern the types of cyberloafing behavior typical of participants in this study and schoolchildren from other countries. In this research schoolchildren more often use access to online content and solve problems of socialization (self-expression and maintenance of significant relations). According to other researchers, students communicate more often during classes via the Internet [26]. Such differences may be related to the age difference of the study participants.

Conflicting data on gender-related differences are found in cyberloafing studies. One study found no differences in cyberloafing levels in people of different sexes $[33,34]$. Other studies report that there may be differences due to differences between men and women in approaches to the use of technology, interests, motivating elements and goals of misuse of the Internet [17, 33]. It is believed that the reason for the inability to detect differences is related to the features of the research group. For example, in our case, it may be the age of respondents. On the other hand, gender differences were found to influence the purpose of media use, including social networking sites [31], 
Table 1. Scale resistance to measurement errors

\begin{tabular}{lll}
\hline factors & number of items & Cronbach's alpha \\
\hline cyberloafing & 27 & 0.936 \\
shopping & 6 & 0.881 \\
accessing online content & 6 & 0.867 \\
activity on social networks & 9 & 0.839 \\
sharing information & 3 & 0.813 \\
socialization & 3 & 0.775 \\
\hline
\end{tabular}

Table 2. Assessing of use of the Internet for personal reasons at lessons at school

\begin{tabular}{llllll}
\hline factors & $\min$ & $\max$ & $\mathrm{M}$ & Skewness & Kurtosis \\
\hline cyberloafing & 1 & 4.27 & 2.5 & 0.04 & 0.66 \\
shopping & 1 & 4.83 & 2.0 & 0.998 & 0.394 \\
accessing online content & 1 & 5 & 3.1 & -0.29 & -0.93 \\
activity on social networks & 1 & 5 & 2.7 & 0.05 & -0.89 \\
sharing information & 1 & 4.83 & 2.0 & 1.31 & 1.13 \\
socialization & 1 & 5 & 3.4 & -0.68 & -0.32 \\
\hline
\end{tabular}

Table 3. Summary of independent samples t-test with regard to gender

\begin{tabular}{lllllll}
\hline factors & Groups & $\mathrm{N}$ & $\mathrm{M}$ & $\mathrm{SD}$ & $\mathrm{T}$ & $\mathrm{p}$ \\
\hline cyberloafing & male & 64 & 2.4 & 0.82 & -0.96 & 0.34 \\
cyberloafing & female & 86 & 2.5 & 0.74 & -0.96 & 0.34 \\
shopping & male & 64 & 2 & 1.1 & -0.04 & 0.97 \\
shopping & female & 86 & 2 & 0.98 & -0.04 & 0.97 \\
accessing online content & male & 64 & 3.1 & 1.2 & 0.56 & 0.58 \\
accessing online content & female & 86 & 3.02 & 1.04 & 0.56 & 0.58 \\
activity on social networks & male & 64 & 2.5 & 1.04 & -2.54 & 0.01 \\
activity on social networks & female & 86 & 2.9 & 1.08 & -2.54 & 0.01 \\
sharing information & male & 64 & 1.93 & 0.86 & -1.01 & 0.314 \\
sharing information & female & 86 & 2.07 & 0.75 & -1.01 & 0.314 \\
socialization & male & 64 & 3.04 & 1.12 & -3.53 & 0.001 \\
socialization & female & 86 & 3.65 & 0.99 & -3.53 & 0.001 \\
\hline
\end{tabular}

features of self-presentation in networks [35], choice of content [36].

Many studies suggest that men exhibit cyberloafingrelated behaviors more often than women, both in workplaces and in educational institutions [35]. Turkish researchers explain these gender differences in Internet use. They note that according to a recent national report in Turkey, the number of male Internet users exceeds the number of female users [26]. Researchers suggest that the habit of using the Internet men will carry and at the place of work or study. However, gender differences in Internet use and cyberspace can also be controversial. For example, gender differences may vary depending on the type of cyberloafing [26]. This has also been confirmed in our study. Gender differences in cyberloafing behavior can also be influenced by the nature of the target audience [33] and the inclusion of control variables such as social desirability [26].

Analysis of gender differences on individual cyberloafing factors showed that men have higher scores on scales: shopping, access to online content and games [26]. Another study found that women are more likely than men to use smartphones to both distract and achieve educational goals [27]. Our study found that girls are more likely than boys to attend social media during lessons and use the Internet to solve socialization problems. These differences can be explained by the fact that psychological characteristics related to sex determine the general activity of the person, including information [37].

\section{Conclusion}

The results of the study conclude that study participants rarely use Internet technologies for personal purposes during classes. They are distracted to communicate with friends or find interesting information. It was found that cyberloafing behavior differs among school students of different sexes.

The study presented has a number of limitations. The study used self-accounts as a data collection tool. They have the following limitations: inconsistent or socially desirable responding [38]. Another limitation is that the scale used does not take into account a kind of cyberloafing behavior like gamming.

Despite the limitations described above, the study presented is the first conducted in Russia. Its results are of interest to the organization and further study of cyberloafing in our country. 
Conducting a survey during the summer holidays could affect the results of the study too. Therefore, more research is required on cyberloafing in conditions closer to natural ones. It is promising to study cyberloafing during distance learning, as measures to prevent the spread of COVID-19.

\section{References}

[1] G. Durak, The International Review of Research in Open and Distributed Learning 18, 84 (2017)

[2] N. Sivrikova, E. Harlanova, E. Stolbova, A. Ageev, Revista Dilemas Contemporáneos: Educación, Política y Valores VI (2019)

[3] K. Kian-Yeik, Pertanika Journal of Social Sciences and Humanities 26, 409 (2018)

[4] F. Sana, T. Weston, N.J. Cepeda, Computers and Education 62, 24 (2012)

[5] J. Wu, W. Mei, J.C. Ugrin, Cyberpsychology, Behavior, and Social Networking 21, 199 (2017)

[6] M.R.R. Gallego, A.L. Martínez, I.M. Herrera, PixelBit. Revista de Medios y Educación 50, 77 (2017)

[7] V.K. Lim, J. Organ. Behav. 23, 675 (2002)

[8] B.K. Mercado, C. Giordano, S. Dilchert, Career Dev. Int. 22, 546 (2017)

[9] K.Y. Koay, P.C.H. Soh, K.W. Chew, Manag. Res. Rev. 40, 1025-1038 (2017)

[10] N. Derin, S.G. Gökçe, Procedia - Soc. Behav. Sci. 235, 694-700 (2016)

[11] G. Bock, S.C. Park, Y. Zhang, Journal of Computer Information Systems 50, 150 (2010)

[12] B. Corgnet, R.H. Gonzalez, R. Mateo, PLoS One 10 (2015)

[13] E. Lowe-Calverley, R. Grieve, Cyberpsychology 11 (2017)

[14] L. Khansa, R. Barkhi, S. Ray, Z. Davis, Information Technology and Management 19, 150 (2018)

[15] J.C. Ugrin, J.M. Pearson, S.M. Nickle, Journal of Internet Commerce 17, 46 (2007)

[16] S. Pindek, A. Krajcevska, P.E. Spector, Computers in Human Behavior 86, 147 (2018)

[17] H.Y. Durak, M. Saritepeci, The Social Science Journal 56, 69 (2019)

[18] M. Saleh, I. Daqqa, M.B. AbdulRahim, N. Sakallah, International Journal of Advanced and Applied Sciences 5, 87 (2018)

[19] M. Anandarajan, P. Devine, C.A. Simmers, Personal Web Usage in the Workplace: A Guide to Effective
Human Resources Management (IGI Global, USA, 2004), chap. A Multidimensional Sealing Approach to Personal Web Usage in the Workplace, pp. 61-79, ISBN 9781591401483

[20] A.L. Blanchard, C.A. Henle, Computers in Human Behavior 24, 1067 (2008)

[21] S. Yaşar, H. Yurdugül, Procedia - Social and Behavioral Sciences 83, 600 (2013)

[22] E. Varol, Technol. Knowl. Learn 24, 129 (2019)

[23] I.B. Arabaci, TOJET 16 (2017)

[24] L. Yuwanto, Psychology Research 8, 173 (2018)

[25] F.G. Karaoğlan Yılmaz, R. Yılmaz, H.T. Öztürk, B. Sezer, T. Karademir, Computers in Human Behavior 45, 290 (2015)

[26] Y. Akbulut, O. Dönmez, Özcan Özgür Dursun, Computers in Human Behavior 72, 87 (2017)

[27] E. Ergün, A. Altun, Educational technology theory and practice 1, 36 (2012)

[28] Şahin Gökçearslan, Çelebi Uluyol, S. Şahin, Children and Youth Services Review 91, 47 (2018)

[29] N. Sivrikova, S. Roslyakova, N. Sokolova, E. Moiseeva, SHS Web of Conferences 70, 06010 (2019)

[30] E. Fu, Q. Gao, C. Wei, Q. Chen, Y. Liu, J. Comput. Assist. Learn 37, 91 (2021)

[31] H.Y. Durak, Journal of Educational Computing Research 58, 539 (2020)

[32] Öznur Tanrıverdi, F. Karaca, ADDICTA 5, 285 (2018)

[33] Y. Akbulut, Özcan Özgür Dursun, O. Dönmez, Y.L. Şahin, Computers in Human Behavior 55, 616 (2016)

[34] K. Askew, J.E. Buckner, M.U. Taing, A. Ilie, J.A. Bauer, M.D. Coovert, Computers in Human Behavior 36, 510 (2014)

[35] U. Oberst, V. Renau, A. Chamarro, X. Carbonell, Computers in Human Behavior 60, 559 (2016)

[36] R. Martín-Guart, J.F. Cavia, Prismasocial 1, 209 (2016)

[37] E. Moiseeva, N. Sivrikova, E. Ekzhanova, E. Reznikova, Gender and Age Features of Media Consumption: Results of the Survey of People Aged 12-20, in Proceedings of the XI International Scientific Conference Communicative Strategies of the Information Society (Association for Computing Machinery, New York, NY, USA, 2019), CSIS'2019, ISBN 9781450376709

[38] M.H. Baturay, S. Toker, Computers in Human Behavior 50, 358 (2015) 